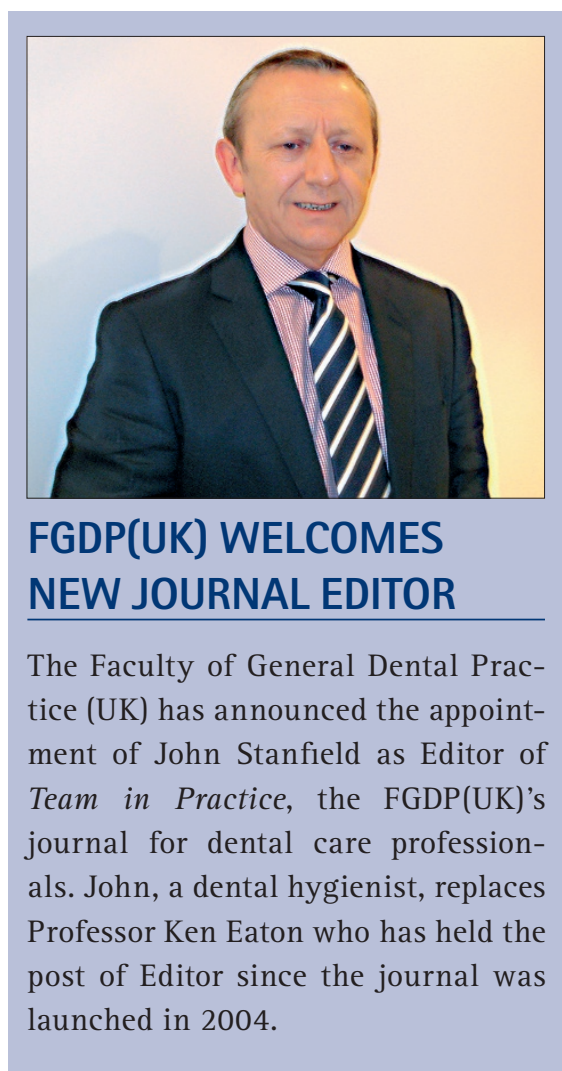

\section{FOUNDER'S ACHIEVEMENTS COMMEMORATED}

A plaque in honour of Professor Shahram Tabibi who founded the Institute for Postgraduate Dental Education at the University of Central Lancashire (UCLan) was unveiled at a commemorative day held at UCLan recently.

The Pro-Vice Chancellor and Colleagues from UCLan attended the event in recognition of the achievements of an innovative and forward-thinking peer. Pro-Vice Chancellor Eileen Martin said, 'When Professor Tabibi joined the University in 2003, there was no dental activity at UCLan at all. He has made an outstanding contribution to the development of dentistry at the University.'

Registered Specialist in Oral Surgery, Professor Shahram Tabibi has worked closely with Professor Martin since 2003. He introduced the very first clinical dental course to UCLan and worked as Senior Lecturer and Internal Examiner for this course.

In 2006, he was appointed as Head of Department to establish an Institute for Postgraduate Dental Education providing excellence through skill to dentists wishing to embark on further training. Core

\title{
GDC APPOINTS NEW CHIEF EXECUTIVE AND REGISTRAR
}

Evlynne Gilvarry has been named as the new Chief Executive and Registrar of the General Dental Council (GDC). She will take up the position later in the year. A qualified lawyer and mediator, she will join the GDC from the General Osteopathic Council (GOsC), the statutory regulator of osteopathy in the UK, where she is currently Chief Executive and Registrar. She has held this post since November 2007. Previously she worked in various senior policy and management roles at the Law Society, the regulator and professional body for solicitors in England and Wales.

Evlynne Gilvarry said, 'I am very pleased to take up this appointment and look forward to working with the staff and the Council of the GDC to deliver an excellent performance.
Alison Lockyer, Chair of the Council of the GDC said, "We will be working closely together as we develop the strategy for the council and improve our performance in Fitness to Practise.'

In further GDC news, David Murphy has been appointed to the Council of the GDC with immediate effect. He is a returning lay member of the Council, having previously served between 2003 and 2009. He is one of 24 members, 12 lay and 12 professional.

David is currently Deputy Secretary of NILGOSC, the Northern Ireland Local Government Pension Scheme and previously held positions with Methodist College, Grant Thornton, and Queen's University Belfast. He is a Fellow of the Institute of Chartered Accountants in Ireland.

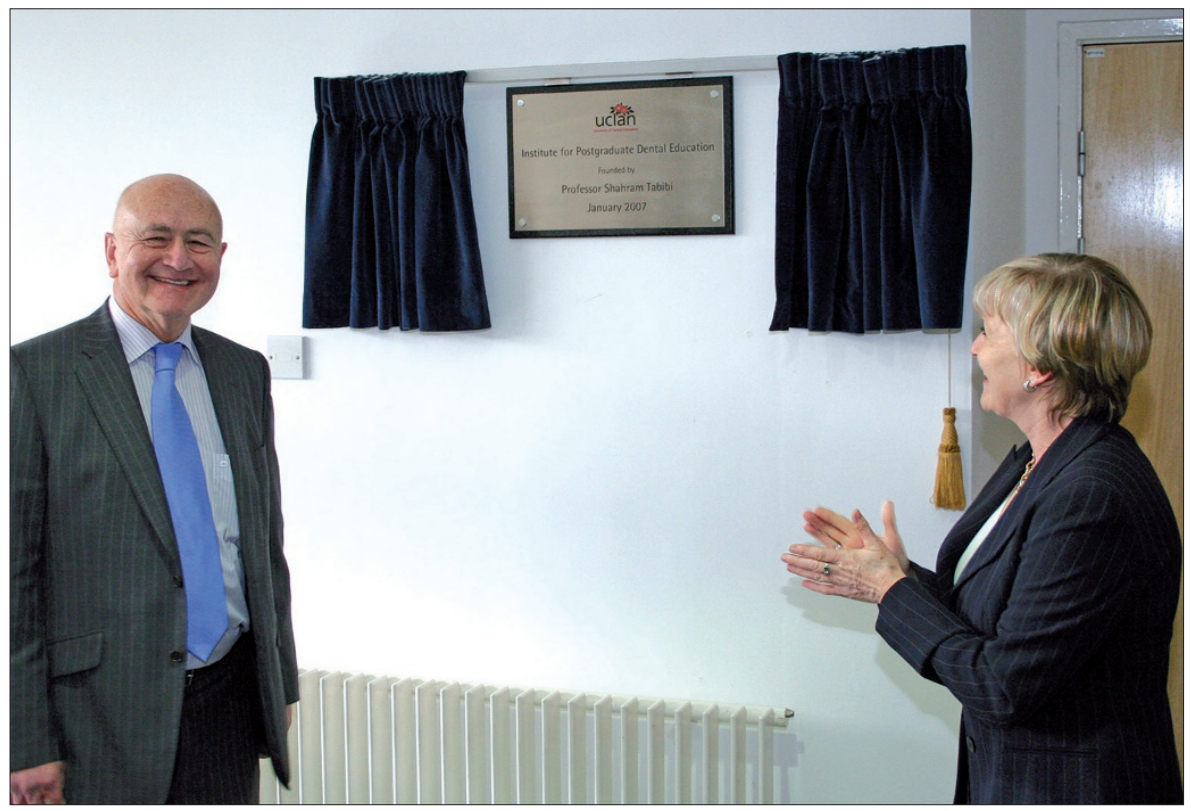

Left Professor Sharam Tabibi, right Pro-Vice Chancellor Eileen Martin

disciplines included MSc programmes in implantology, restorative cosmetic dentistry, periodontology, oral surgery and endodontics, and a Certificate of Higher Education in orthodontic therapy.

Professor Tabibi was instrumental in developing initial relationships between UCLan and the GDC and the Faculties of General Dental Practitioners. UCLan was successful in their bid for an Undergraduate Dental School in 2007.
His significant achievements in changing the arena of dental education were recognised by his Personal Professorial Chair at UCLan. Professor Tabibi's professional commitments have not just been aimed at his own development, but also that of his colleagues. UCLan's commemoration of his efforts was a nod to the motivation of someone who has placed others' development ahead of his own personal endeavours. 